\title{
INTEGRATION IN THE EDUCATIONAL SYSTEM IN ISRAEL AND ITS INFLUENCE ON SOCIAL STRATIFICATION IN A CHANGING WORLD
}

\begin{abstract}
AвSTRACT. Franco Manor Sali, Integration in the Educational System in Israel and Its Influence on Social Stratification in a Changing World [Integracja w systemie oświaty w Izraelu i jej wpływ na rozwarstwienie społeczne w zmieniającym się świecie]. Studia Edukacyjne nr 46, 2017, Poznań 2017, pp. 439-449. Adam Mickiewicz University Press. ISSN 1233-6688. DOI: 10.14746/SE.2017.46.28
\end{abstract}

Among the phenomena that characterize modern society it is possible to note the appearance of complex political, occupational, and sectorial systems of status and the weakening of the 'class' factor in its ideological meaning. The main result of this development was the steadily increasing conflict between, on the one hand, the trends of economic development and the new centers of power and, on the other hand, the mobility of new groups. All the groups competed among themselves over the additions of income, accessibility to economic resources, and positions of influence in the government system as well as over the creation of autonomous frameworks.

An important part in these sectorial formations is related to the positioning of education in the entire stratified system. The statement that the extension of education has not resulted in the reduction of social gaps in the professional field, especially between employees, is correct, yet conversely it did drive a process of change in the evaluation of different subjects and a change in the perception of education as a necessary state of specialization. This aspect constitutes an important factor in the processing of the stratified map and in the formation of the class awareness. The education systems, which are the main organizations to inculcate education, can determine who is qualified and who is not qualified to fill different employment roles; they have become the main device for the achievement of social and economic status.

Key words: integration, educational, Israel, stratification, economic status

The educational system educates, trains, and inculcates values, and enables social mobility and access to stratifying resources in society. Education constitutes an important step in the determination of the level of income, instills prestige and respect, in the social aspect and access to focuses of political power and influence. 
The government, since it is responsible for the shaping of the values of the educational system, will determine the appearance of future society. The mass immigration to Israel in the 1950s and 1960s, a large part of which came from the countries of the Middle East and North Africa (Mizrachi Jews), emphasized the differences in the level of education between them and people from Europe (Ashkenazi Jews). The job market became stratified, when people of European extraction hold the more senior positions because of their better socioeconomic status, lower residential density, higher income per capita, and closeness to the leading social sector. The members of the different classes come to the school with a different cognitive or cultural 'capital'. This difference influences the children's initial achievements, but the differences tend to be strengthened following the families' different degree of ability to follow up after the learning weaknesses and to treat them effectively.

The educational system is one of the important tools for the bridging over the gaps and for socioeconomic equality. In July 1968 the State decided upon an intentional policy of integration in education, in another, complementary attempt to increase equality and social integration. In this framework (the reform), the middle schools were established, intended to postpone the date of the classification for the high school and to cause students from different backgrounds to meet in the school setting. In the middle school, students from well-off urban schools sit with students from the higher groupings in the neighborhood schools. According to the researchers, a heterogeneous study environment will cause motivation and high achievements for all the neighborhoods and will eliminate barriers on a social and ethnic background.

The integration began at a relatively late age, was not fully implemented, was without the appropriate preparation of the teacher staff and the parents, and sometimes was implemented incorrectly, thus causing segregation and regression. The educational system succeeded in improving to some extent the structure of education of the population. The following questions are asked: Was the process effective and successful and did the method change the stratified position of the different groups to an extent that justifies the resources of capital and time invested in it? Did the method of integration that was implemented by the educational system in Israel in an era of changes achieve its goal and contribute to the reduction of the social gaps and the promotion of the weak groups?

In the end, "the education of those who are not found in the elite is difficult to clearly justify and tends to be done not whole-heartedly, while most of the educational resources are concentrated among those who can enjoy them more." 1

${ }^{1}$ R.H. Turner, From the Ways of Social Advancement through Education - Implicit Mobility and Competitive Mobility, [in:] R. Shapira, R. Poleg, The Sociology of Education, Tel Aviv 1989, p. 227. 
In Israel, on the declarative level education is equal for all but in essence education is far from equality and there exist in it many aspects of mobility. The Free Education Law, the reform, the integration, the change of the method of classification (survey and high school matriculation examination), and the extension of the circle of learners tend to the direction of equality and competition. However, conversely we see the opposite process of residential schools and vocational and agricultural schools, where in essence the student's track of mobility is determined.

The State of Israel, from the social needs considered by the state leaders to be essential, attempts to correct the distortion and to promote members of the weak groups, sometimes at the expense of the rest of the groups. It is possible that these goals justify social and educational intervention on a national scale, but sometimes there is a feeling of harm to democracy and to the individual's freedom of choice.

The system constitutes an important and main tool in its importance only to the initial values of the family in the inculcation of formal education and internalization of stratified norms. The government will put forth a constant effort to adjust the educational systems to the norms of mobility existing in it. These systems, which include public schools, private schools, gray education $^{2}$, extrinsic education, etc., will internalize the values of mobility and stratification. The importance of the educational system is in its overall scope and its exclusivity in the setting of emphases in topics of tracks of education, training, bundles of education services, choice of the staff, and teaching methods.

The referral of the members of the different groups to the channels of education agreed upon by the government, the inculcation of the level of education, the quality of grades, the emphases, and number of years of learning instilled by the public system are what determine the graduate's initial and unequal beginning path and serve as the individual's primary means of mobility. Education and level of mobility are responsible for the stratified structure of society since they are a classifying factor, in an overt or covert manner, between the groups referred to manufacturing and the groups referred to clerical work, etc. The type and level of education are directly related to the learner's personal subjective level and to the objective conditions of his parents' education and income, their cultural level, and the support the individual receives in his primary environment.

These factors are stratifying factors, which bring the system into a closed circle of those who have the means to provide higher education for the second generation, and thus their cultural status is set. The system has a general monopoly on the inculcation of knowledge but as it tends to rely more on the

\footnotetext{
${ }^{2}$ Education at the parents' expense (private lessons).
} 
family cultural inheritance, there is greater emphasis on the cultural level, the levels of leisure activity, and the proper symbolic expressions so as to convey this heritage to the students. To prevent ethnic-class unquiet and to promote their issues, there is the prevention of the participation of whole groups in the cultural experience, in an implicit but supposedly democratic manner by the groups with the cultural capital.

The rules for success are determined according to the priorities that the educational system determines for itself with the help and direction of the government system and the system of norms. The idea behind this policy is to allow as many students as possible reach a high stage in the competition, or in other words, occupational equality of opportunities. Education is for professionalism, and is a guide for adjustment in a changing, nonhomogeneous world.

There are a number of main organizations that influence the rules according to which success in the educational system is determined: the political organization and the organizing norm, external influences of those with cultural capital, internal manpower of the system, the political organization is supposed to be on guard and to warn of undesired social developments. One of the important tools in the change or preservation of norms is education of the new generation. Generally the political establishment and the system of norms nurture one another. Thus, the establishment will tend to stability and conservatism so as not to shock the entire system. Of course, when the developments are observed that may endanger the political system or the system of norms for any reason, whether social or economic, such as undesired groups and groups with economic problems, and internal unrest, the establishment will intervene and will change the order of priorities of the educational system through the change of the rules for success. The academic world that is afraid of over-investments in the economic measures will limit its power, will attempt to be balanced in its recommendations, but always will be apparent the direction to increase the importance of the culture at the expense of the professionalism.

Another organization that influences the rules of success and distances from it the 'other' groups is the system of those with cultural capital. According to Bourdieu ${ }^{3}$, those with cultural capital, namely, the authors, the playwrights, the critics, constitute an important step in the determining of the priorities. These people are close to the educational system and utilize it for them and for their children. The principle that guides them is that the pedagogical product that the different groups receive from the system should be parallel in values to the level of cultural capital at their disposal. Therefore,

3 P. Bourdieu, R. Brown (Eds.), Knowledge, Education and Cultural Change, London 1973, p. $71-112$. 
the students who will derive the most benefit from the educational system are those who have the cultural inheritance from the home. They understand the language of culture and are exposed to studies and reading from childhood. The immediate victims are the students without the proper cultural-family relationships. The rules for success will not be equal and will tend to the accepted cultural side as opposed to the other possible achievement sides. In this situation, in which not just the academic certificate grants the right of entry to the important positions, Bourdieu proves that in essence there is no relationship between education and the fulfillment of the power of education. Moreover, as there is distance from the districts of education to other systems, the certificate loses its power and in the end serves only as an accelerator and stamp for the regular mobility, which relies on other relationships.

The last organization of influence is the internal manpower of the system. Their opinion and experience have great weight in determining the rules for success. However, when failures are apparent, they are the organization that is criticized, but they are the organization that operates in the field and implements the dictated policy. This is in essence a cycle in which those with cultural capital influence the teaching workers, who are nurtured from them and influence the next generation.

The role of the educational system in Israel is not only to provide certificates for mobility. The principles of education are based on values of education, love of Israel, pioneering, equality, reciprocal assistance, and central values of tolerance towards all ethnic and class groups. The educational system was assigned the task of the design of the stratified system from a view of inequality and gap between the ethnic groups as an obstacle for the establishment of the state. Smilansky ${ }^{4}$ best expressed the view of the system as creating a chance for mobility and eliminating gaps: the insertion of weak ethnicities and groups into technical and upper high school education means socially the direction in a certain period of time to certain attitudes in the social and economic mechanism.

Equal education must have the meeting between different social and economic strata, between the more talent and the less talented. For this purpose, the educational system implemented a reform system, which calls for equal education, for the increase of the general level, and for integration - even if this is at the expense of excellence and professionalism. Unfortunately, the reform in education did not achieve its objectives for the realization of the equality of rights and the chances of mobility. Stereotypic opinions became more moderate, but real progress was not achieved. Homogeneous groups still exist, and the certificates granted by prestigious schools, affiliated with

\footnotetext{
${ }^{4}$ M. Smilansky, The Social Examination of the Structure of Education in Israel, Trends, 1957, 8.
} 
certain elite neighborhoods, are still excessively important. In these schools, the students convert socioeconomic benefits into scholastic achievements, and these achievements are recognized as giving better chances of mobility than the same certificates from other schools.

While in the year 1948 those of Mizrachi origin constituted about 23\%, in the year 1964 their number increased to $52 \%$ of the total population. The increase of their absolute and relative number did not result in social-economic equality and their achievements in the realm of education were low.

The students who are members of the different classes reached the school with a cognitive mindset and cultural capital. While this mindset tends to be blurred in the future, in the beginning it influences the scholastic achievements and the ability of the parents to follow up after the students' achievements. The concentration of the members of the lower classes in designated or regional schools, the low morale of the teaching staff and parents, the low level of teaching, and low bargaining power and knowledge of the parents from the weak sectors contribute to low morale and self-fulfilling prophecies and cause a decline in the learning achievements and a low self-value of the students. In parallel to the group of workers, there developed a social group of factory owners, industrialists, and engineers, who enjoyed diverse possibilities of advancement. This group was mostly the natives and their children who had acquired a higher education. ${ }^{5}$ These developments contradicted the ideology of the 'melting pot' and 'merging of exiles'. The hope that the differences between the ethnic groups would vanish over the years was proven false. The gaps from the 1960s were not closed in the 1970s as well.

Mean Annual Income of Urban Employed Families, by Origin of Family Head (Central Bureau of Statistics, 1975, 1977)

\begin{tabular}{|l|c|c|}
\hline & $\mathbf{1 9 6 5}$ & $\mathbf{1 9 7 6}$ \\
\hline ALLFamilies & 7800 & 44000 \\
\hline Mizrachi Origin & 6200 & 38400 \\
\hline Ashkenazi Origin & 8600 & 46900 \\
\hline
\end{tabular}

The gradual release from existential problems, such as housing and livelihood, work and security, emphasized the ethnic gaps. Israeli society rejected genetic explanations and emphasized the need for equality. At first we see the local organizations and initiatives of the school staffs and the parents' committees so as to promote the idea. However, the initiatives, since they are local, lack resources and are fated to fail.

\footnotetext{
${ }^{5}$ S.R. Sabirsky, Education in Israel - District of the Separate Tracks, Tel Aviv 1990, p. 87-102.
} 
The formal educational system does not succeed in bridging the educational gaps and the generational and intergenerational inequality between the different ethnic groups and labels the Mizrachi immigrants, even before they immigrate, as disadvantaged. The definition of the children as disadvantaged is discriminatory, treating them in terms of inferiority and superiority and assuming that there exists only one culture and everything is assessed relative to it. The attitude towards the 'disadvantaged children' is that they are backwards, unready, and without learning motivation. The children are alienated from the cultural and social environment of the school, in which the middle class is dominant, and become lacking in initiative and tending towards failure and lack of adjustment. The system channels these groups to low groupings and short-term and vocational learning tracks that perpetuate their low socioeconomic status and do not allow the large majority of those of Mizrachi origin to acquire a high school matriculation certificate and obtain a higher education.

Towards the end of the 1970s, high school matriculation tracks were created in the professional programs and the prestige of some of these tracks, for example electronics and computers, increased. This trend contributed to the increase of the number of students who complete high school with the matriculation option. Nevertheless, in these years students were still directed to the different tracks according to origin.

Another method that the system adopted is groupings. The students in the heterogeneous class are divided into homogenous groups according to learning level and achievements. The goal is the coping with the heterogeneous class and the attempt to promote the weak groups. Research studies showed that the progress of all the students at the high grouping levels populated mostly by those of European origin is relatively greater than the progress of the lower groups. Namely, instead of reducing scholastic gaps the method increases them. In addition, the method causes further social differentiation of the students, differentiation that is strengthened by ethnic characteristics.

The recognition of the importance of integration as a device for the promotion of education and the reduction of the ethnic groups arose at the end of the 1960s and strengthened at the start of the 1970s. At first, the idea was only one part of a number of objectives in the reform program of the Ministry of Education - "to have the children meet in regional learning frameworks" (Rimlet Committee). In the continuation, a committee was formed that clearly announced the integration as the "acceleration of the processes of social integration of different ethnicities and classes" and formulated detailed ways of action. The Parliamentary Committee that was established to examine the topic submitted a law proposal on May 29, 1969 and recommended that "the regional middle school will serve as a place of meeting for the children of 
Israel from all classes and ethnic communities. The elementary school is as usual a neighborhood school, or in other words, in most cases homogeneous in terms of the social or ethnic composition of the population of students who learn in it. The middle school will be either regional (for small communities that also are, for the most part, homogeneous in terms of the composition of residents) or by district in the cities. The registration districts for the middle schools in the cities will be drawn from the start so that in most cases the population of the students in it will be diverse and not from one social region. The committee saw the meeting of children of parents from different classes and countries of origin at least from the age of twelve in one school not only as a necessary means for the reduction of the gap in the level of education between the children of the nation but also as a national value in its own right."

The preparation of the educational system was slow but was validated towards the end of 1971, when a new law for the merging of schools was passed and granted the Minister of Education extensive authorities so as to enable the ministry to move the wheels of integration. The operational recommendations were published only in August 1975. The range of problems, reservations, and questions was extensive and postponed the implementation for a long time. Primarily the parents of European origin in the well-off communities had reservations and decided to shift their children from the integrative schools to other schools. The Minister of Education published in December 1976 an order that obligated the students' parents to return their children to the original schools. The supporters of the program did not always rely on the same explanations. Some of them saw it primarily as a device for the achievement of goals such as the reduction of gaps, improvement of scholastic achievements, social process, etc. Others saw the program to be a goal in its own right, an expression of the ideology of equality and cohesion. Experience showed that the use of integration does not always achieve its goals, and thus the trend strengthened to see the program to be a goal in the boundaries of the national consensus. The very seating of students from the different ethnic groups one beside the other is supposedly the achievement of the goal. The shift of the emphasis in the policy enabled the Ministry of Education to indicate achievements in the field of integration, although some of the main objectives, such as the closing of scholastic and social gaps, were not achieved.

The geodemographic reality is the existence of large communities in nearly homogeneous regions in ethnic terms. Prominent examples are the moshavim (rural residential communities) and many of the development towns, which include more than half a million people and are clearly Mizrachi. If the resources for extensive transportation programs are not found, then large parts of the population, who are mostly a specific target of the program, cannot participate in it. The economic situation of the State of Israel in general 
and of the Ministry of Education in particular did not contribute to the realization of the program. Problems financing the transportation, acquiring the new curricula, training the teachers, and building new middle schools caused the school principals to wonder whether the limited means in existence would not be better used if they were directed to the development of existing infrastructure. A large number of the teachers objected to the implementation of the program for technical reasons - the teacher must adopt for herself alternative learning methods that will help her promote all the students and maintain a reasonable setting and learning atmosphere. However, the implementation of new teaching methods is not easy and obligates a fundamental change in the perception of the teaching and the roles of the teacher and the students in the learning process. Lacking these, the teacher will find it difficult to cope with the heterogeneous class, and the pressure to create homogeneous groupings will increase. On the part of the management, the school principals were concerned about the school name with the decline of the means of the scores and the entrance bar according to the requirement of the Ministry of Education.

Established parents from a Western origin feared that the practical interpretation of the integration is a decline in the level of education in comparison to the level that their children would receive in separate frameworks in homogeneous schools. This group, whose children succeed in the homogenous school and receive both better education services and greater educational credit for the continuation of their scholastic and social advancement, sees the political integration that may undermine its social achievements and its ability to maintain these achievements. Thus, the argument of 'mediocrity' and loss of the chance for the development of future talents is raised. The parents began to display active opposition with the beginning of the program, and this was expressed in the strikes and removal of their children to private and semi-private education. In an atmosphere where there is the strong fear for the level of scholastic achievements and loss of the ethnic uniqueness, the support of the program was weakened. In this situation, the parents from the two groups adopt active resistance by bypassing the system. As of today, in an atmosphere of ethnic, political, economic, religious, and social polarization, it is difficult for the system to implement the system in its entirety.

The listing of the achievements and failures is derived from the manner of the definition of the goals and the groups intended by the program of integration: to provide equal opportunity for all the students, to improve the scholastic achievements of disadvantaged students, to change attitudes between different populations in Israeli society, to cultivate social relations between students from different sectors, to improve the self-image of the weak groups. Integration is a goal in its own right for the purpose of the maximum merging 
between the different ethnic communities and sectors as a supreme national value. This goal is achieved through its existence.

It was decided to implement the reform in 1968, when the Knesset accepted the recommendations of the committee for the examination of the structure of elementary and secondary education in Israel. The emphasis was dual: integration as a political goal in its own right and as an educational means for the promotion of the weak groups and the change of social attitudes. Since the decision, there were better and worse periods in the implementation of the program and after four decades it is possible to summarize its results. There is no apparent difference in the scholastic achievements of middle school students and those of elementary schools at the same level. The middle schools contributed very slightly to the increase of the percentage of students who obtain a high school matriculation certificate. Generally the attitude to the program is positive. However, there are groups of parents, teachers, and principals who support steps that contradict the spirit of the program, such as the use of groupings, the referral to special classes, strikes, etc. The influences on the psychological measures such as self-image, scholastic and occupational aspirations, were not especially strong and sometimes were even negative.

The program of educational merger and social mixture exacerbates the issue of the coping with the problem of the heterogeneity in Israeli society and strengthens the tendency towards the implementation of segregation so as to maintain the supply of good students. There is no empirical confirmation of the assumption that the program contributed significantly to the increase of the scholastic achievements of the different groups. Despite the reduction of the initial gap, there still is a large gap in the field of the scholastic achievements between the disadvantaged and the strong groups. In addition, the gap between the different groups in the field of higher education was not reduced beyond what was obligated by the change of the character and composition of the population; thus it constitutes a main obstacle in the chances of mobility of the groups in Israeli society.

Additional questions such as the promotion of the weak at the expense of the strong, the cultivation of mediocrity at the expense of excellence, the harm to the intellectual aspirations of the different groups, the harm to the freedom of the individual and freedom of choice versus dictates from above, the blossoming of grey education, and the radicalization and accentuation of polarization in society remained open, without sufficient emphasis regarding their future implications.

As of today, after the tremendous investments in financial and social resources, the balance statement does not indicate justification of these investments. The integration program did not achieve its goal, not as a means for the reduction of scholastic and social gaps and not as a goal in its own right. 
It is possible that if the funds and effort had been invested in the previous system, with localized emphasis on the places that require a different approach or perception, then better outcomes would be obtained.

\section{BIBLIOGRAPHY}

Bourdieu P., Brown R. (Eds.), Knowledge, Education and Cultural Change, Tavistok, London 1973.

Central Bureau of Statistics (1975). Statistical Annual of Israel, 26, 262.

Central Bureau of Statistics (1977). Statistical Annual of Israel, 28, 271.

Eilam B., Finegold M., The Heterogeneous Class: A Solution or Just Another Problem? Studies in Educational Evaluation, Haifa University, 1992.

Eshel Y., Klein Z., Elementary School Education and Open Education, Scripta Hierosolymitana, 1995, 36, Haifa University.

Klein Z., Eshel Y., Integration and Promotion of the Goals of Education in Israel, Trends, 1981, 26(3).

Nahon Y., Patterns of the Extension of Education and Structure of Employment Opportunities: The Ethnic Dimension, Jerusalem Institute for the Research of Israel, Jerusalem 1987, 25.

Sabirsky S.R., Education in Israel - District of the Separate Tracks, Britot, Tel Aviv 1990.

Smilansky M., The Social Examination of the Structure of Education in Israel, Trends, 1957, 8.

Smilansky M., Yam A., The Relationship between the Family Size, the Father's Education and the Father's Origin, and the Cognitive Abilities and Scholastic Achievements, Trends, 1969, 16.

Tiomin M.M., A Number of Principles of Social Stratification: A Critical Analysis, [in:] M. Lisk, Issues in Sociology, Am Oved, Tel Aviv 1973.

Turner R.H., From the Ways of Social Advancement through Education - Implicit Mobility and Competitive Mobility, [in:] R. Shapira, R. Poleg, The Sociology of Education, Am Oved, Tel Aviv 1989. 